\title{
Residential Construction Site Selection Through Interval-Valued Hesitant Fuzzy CODAS Method
}

\author{
Ali KARASAN ${ }^{1,3 *}$, Edmundas Kazimieras ZAVADSKAS ${ }^{2}$, \\ Cengiz KAHRAMAN ${ }^{3}$ Mehdi KESHAVARZ-GHORABAEE ${ }^{4}$ \\ ${ }^{1}$ Graduate School of Science and Engineering, Yildiz Technical University, Esenler, \\ Istanbul, 34220, Turkey \\ ${ }^{2}$ Department of Construction Technology and Management, Faculty of Civil Engineering, \\ Vilnius Gediminas Technical University, Lithuania \\ ${ }^{3}$ Industrial Engineering Department, Istanbul Technical University, Besiktas, \\ Istanbul, 34367, Turkey \\ ${ }^{4}$ Department of Management, Faculty of Humanities (Azadshahr Branch), \\ Gonbad Kavous University, Gonbad Kavous, Iran \\ e-mail:akarasan@yildiz.edu.tr,edmundas.zavadskas@vgtu.lt,kahramanc@itu.edu.tr, \\ m.keshavarz_gh@yahoo.com
}

Received: January 2019; accepted: September 2019

\begin{abstract}
Construction site selection is a complex problem involving many alternatives and conflicting criteria with vague and imprecise evaluations. Fuzzy multi-criteria decision-making methods are the most effective tools to obtain optimum solutions under possibilistic uncertainty. In this paper, a novel interval hesitant fuzzy CODAS method is proposed and applied to a residential construction site selection problem. A comparative analysis with ordinary fuzzy CODAS method is applied for validating the proposed method. Also, a sensitivity analysis is conducted for the stability of the ranking results of the interval hesitant fuzzy CODAS method. The results of the analyses demonstrate the effectiveness of our proposed method.
\end{abstract}

Key words: construction site, multi-criteria, CODAS, hesitant fuzzy sets, selection problem.

\section{Introduction}

Selection of the most suitable site for a residential area is one of the conditions determining the quality of living in urban cities. Residential construction site selection problem requires operational, environmental, social, and economic criteria to be considered in the assessment process. These criteria may be intangible, tangible and conflicting with each other. The assessment process is generally realized under vague and imprecise environment, which justifies the usage of the fuzzy set theory.

Residential construction site selection problem can be solved by a multi-criterion decision-making (MCDM) method. MCDM methods help decision-makers to subjectively evaluate the performance of alternatives with respect to the predetermined criteria (Zavadskas et al., 2004, 2014). In the literature, there are many MCDM methods

\footnotetext{
*Corresponding author.
} 
such as Analytic Hierarchy Process (AHP) (Saaty, 1980), Technique for Order of Preference by Similarity to Ideal Solution (TOPSIS) (Yoon and Hwang, 1981), ELimination Et Choix Traduisant la REalité (ELECTRE) (Roy, 1991), Analytic Network Process (ANP) (Saaty, 1996), Evaluation Based on Distance from Average Solution (EDAS) (Keshavarz Ghorabaee et al., 2015), and Combinative Distance-Based Assessment (CODAS) (Keshavarz Ghorabaee et al., 2016). These methods are constructed not only to handle the environmental, human, and social aspects of the problem but also to correctly capture the uncertainties in these aspects. Since residential construction site selection problems involve many uncertainties in terms of vagueness and impreciseness, the best way is to use fuzzy extensions of these MCDM methods.

Fuzzy sets theory was introduced by Zadeh to capture the uncertainties in human thoughts through the degree of memberships of the elements in a set (Zadeh, 1965). In order to increase the capability of handling vagueness and impreciseness in the problems, ordinary fuzzy sets have been extended to many types. Type-n fuzzy sets were developed by Zadeh to reduce the uncertainty of the membership functions in the ordinary fuzzy sets (Zadeh, 1975). Interval-valued fuzzy sets were introduced independently by Zadeh (1975), Grattan-Guiness (1975), Sambuc (1975), Jahn (1975). Intuitionistic fuzzy sets were introduced by Atanassov to show how the hesitancy degree of a decision maker can be handled (Atanassov, 1986). Smarandache developed neutrosophic sets for demonstrating the differences between relativity and absoluteness in the decision makers' preferences (Smarandache, 2005). Hesitant fuzzy sets (HFSs) initially described by Torra (2010) are the extensions of ordinary fuzzy sets where a set of values are possible for the membership of a single element (Torra, 2010). Classical MCDM methods have been extended to their fuzzy versions using these types of fuzzy sets: intuitionistic fuzzy EDAS (Kahraman et al., 2017), ordinary fuzzy CODAS (Keshavarz Ghorabaee et al., 2017), type-2 fuzzy AHP (Kahraman et al., 2014), hesitant TOPSIS (Xu and Zhang, 2013), neutrosophic ELECTRE III. In the literature, setting linguistic scale is essentially realized in two ways: the studies using a constant linguistic scale as in Kwong and Bai (2003), Kulak and Kahraman (2005) and the studies using tools such as mathematical programming or statistical modelling to determine the intervals corresponding to the linguistic terms as reviewing in Liao et al. (2018) and applied in Cabrerizo et al. (2017). Since our paper falls in the studies using a constant linguistic scale, we developed linguistic scales corresponding to fuzzy numbers for our paper.

CODAS is a distance based MCDM method proposed by Keshavarz Ghorabaee et al. (2016). In this method, the overall performance of an alternative is measured by the Euclidean and Taxicab distances from the negative-ideal point. The CODAS uses the Euclidean distance as the primary measure of assessment. If the Euclidean distances of two alternatives are very close to each other, the Hamming distance is used to compare them. The degree of closeness of Euclidean distances is set by a threshold parameter (Keshavarz Ghorabaee et al., 2016). It is quite a new method in the literature but thanks to its advantages it is expected to be used more in the future.

In this paper, a novel hesitant fuzzy CODAS method is developed and applied to the selection of a residential construction site project. The originality of this paper can be 
explained by three items. Firstly, we develop a novel fuzzy CODAS method and apply it to a residential construction site selection problem. Secondly, in the proposed method, the weights of the criteria are obtained by hesitant fuzzy AHP method which makes our approach an integrated methodology. Finally, for validating the proposed method, we compare our results with the results of ordinary fuzzy CODAS method. An explanatory sensitivity analysis is also performed to demonstrate the stability of the ranking results of the hesitant fuzzy CODAS method.

The rest of the paper is organized as follows: In Section 2, a literature review on construction site selection problems is given. In Section 3, the steps of ordinary fuzzy CODAS method are presented. In Section 4, the proposed methodology is clarified with its details. In Section 5, the proposed method is applied to a residential construction site selection problem. The paper ends with conclusions and suggestions for further research.

\section{Literature Review: Construction Site Selection Problems}

Numerous MCDM models have been developed for evaluating construction site location alternatives with respect to the predetermined criteria. We have analysed the studies that can be beneficial for our application and have presented a general evaluation of them. In these studies, MCDM methods are mainly applied for obtaining the solutions of the site selection problems in many different areas.

Cheng et al. (2003) studied MCDM methods to support selection of an optimal landfill site and a waste-flow-allocation pattern. Zavadskas et al. (2004) applied ELECTRE III method for the selection of the best commercial construction project. It is emphasized that MCDM methods are quite suitable for the evaluation and decision-making assessments for construction projects. Dey and Ramcharan (2008) applied AHP method for the site selection process of expansion on limestone quarry operations to support cement production in Barbados. The results show that AHP is an effective method of decision-making and can consider both objective and subjective factors. Turskis et al. (2012) studied the determination of the best construction site alternative for non-hazardous waste incineration plant by using ARAS-F and AHP methods. It can be deducted based on the results that performing more precise assessments is possible with fuzzy sets theory. Balali et al. (2012) applied a new algorithm combining ELECTRE III and Preference Ranking Organization Method for Enrich Evaluation II (PROMETHEE II) for decision-making in the construction management processes. Eskandari et al. (2012) presented a study of landfill site selection problem by integrating geographic information systems (GIS) and AHP method. Hasanzadeh et al. (2013) performed an application of AHP for prioritizing the environmental criteria of coastal oil jetties. The results of the study indicate that ANP findings have a high efficiency for weighting the importance degrees of criteria for environmental construction. Bagocius et al. (2014) presented a study about the selection of the most appropriate location for a liquefied natural gas terminal based on the results of different MCDM methods. Results of the study indicate that outcomes of SAW, TOPSIS, and COPRAS methods are consistent and give similar consequences. Zavadskas et al. 
(2015) applied Weighted Aggregated Sum Product Assessment (WASPAS) method with single-valued neutrosophic sets. The results of the study indicate that applied neutrosophic MCDM method is quite efficient and meets the requirements for the evaluation of intangible factors of the problem. Mousavi et al. (2015) investigated the suitability of the Kish Island coastal areas for the establishment of artificial corals reefs using spatial MCDM tool. Results of the study demonstrated that weighted linear combination method should be used for the identification of alternatives and AHP should be used for the prioritization of alternatives. Chaudhary et al. (2016) studied fire station suitability zonation mapping of Kathmandu City and determined the best alternative using GIS and AHP methods. Since the results reveal that $13.46 \%$ of the considered area is highly suitable for fire station location, zonation map is trustworthy and can be used for the construction of fire stations. Bahrani $e t$ al. (2016) presented a study on landfill site selection by using fuzzy GIS and ordinary AHP. The authors demonstrated that fuzzy functions for landfill site selection were way better than crisp ones for GIS. Bansal et al. (2017) presented a fuzzy decision approach which is a combination of fuzzy synthetic evaluation method and analytic hierarchy process for the selection of most suitable construction method of green buildings. The results show that the proposed model can be an analytical tool to evaluate the applicability of prefabricated or on-site construction methods. Chen et al. (2018) studied another construction site location selection problem by applying EDAS and WASPAS methods. They conducted Monte Carlo simulation to check the sensitivity in changes of the criterion weights.

In this paper, we propose a novel hesitant fuzzy CODAS method which provides flexibility to the definition of membership function and to the measurement of distances from negative-ideal solution. In hesitant fuzzy sets, the difficulty in establishing the membership degrees does not arise from a margin of error or a specified possibility distribution of the possible values but arises from our hesitation among a few different values (Zhang, 2013). Thus, the proposed model can make a comprehensive evaluation in terms of both fuzziness and distance measurement, allowing a more accurate representation of knowledge.

\section{Ordinary Fuzzy CODAS Method}

In this section, preliminaries of ordinary fuzzy sets and steps of ordinary fuzzy CODAS method will be presented.

\subsection{Preliminaries: Ordinary Fuzzy Sets}

Definition 1. If $X$ is a collection of elements denoted by $A$, then a fuzzy set $\tilde{A}$ in $X$ is a set of ordered pairs (Zadeh, 1975):

$$
\tilde{A}=\left\{\left(a, \mu_{\tilde{A}}(a) \mid a \in X\right)\right\},
$$

where $\tilde{A}$ in $X$ satisfies the following conditions: 
- $\tilde{A}$ is normal,

- $\tilde{A}$ is a closed interval for every $a \in[0,1]$,

- The support of $\tilde{A}$ must be bounded,

- $\mu_{\tilde{A}}(a)$ is entitled as the membership function of element a which maps to $X$.

Arithmetic operations of triangular fuzzy numbers are given as follows:

Let $\tilde{A}=\left(a_{1}, a_{2}, a_{3}\right)$ and $\tilde{B}=\left(b_{1}, b_{2}, b_{3}\right)$ be positive TFNs. Then,

- $\tilde{A} \oplus \tilde{B}=\left(a_{1}+b_{1}, a_{2}+b_{2}, a_{2}+b_{2}\right)$,

- $\tilde{A} \ominus \tilde{B}=\left(a_{1}-b_{3}, a_{2}-b_{2}, a_{3}-b_{1}\right)$,

- $\tilde{A} \otimes \tilde{B}=\left(a_{1} b_{1}, a_{2} b_{2}, a_{3} b_{3}\right)$,

- $\tilde{A} \oslash \tilde{B}=\left(a_{1} \div b_{3}, a_{2} \div b_{2}, a_{3} \div b_{1}\right)$.

Definition 2. Let $\tilde{x}=(a, b, c, d)$ be a trapezoidal ordinary fuzzy number. Defuzzification function of this fuzzy number is given as follows (Wang et al., 2006):

$$
\mathfrak{H}(\tilde{x})=\frac{1}{3}\left((a+b+c+d)-\frac{c d-a b}{(c+d)-(a+b)}\right) .
$$

Definition 3. Let $\tilde{x}=\left(a_{1}, b_{1}, c_{1}, d_{1}\right)$ and $\left.\tilde{y}=\left(a_{2}, b_{2}, c_{2}, d_{2}\right)\right)$ be the trapezoidal fuzzy numbers. The weighted Euclidean $\left(d_{E}\right)$ and weighted Hamming $\left(d_{H}\right)$ distances between these two fuzzy numbers are defined as follows, respectively:

$$
\begin{aligned}
& d_{E}(\tilde{x}, \tilde{y})=\sqrt{\frac{\left(a_{1}-a_{2}\right)^{2}+2\left(b_{1}-b_{2}\right)^{2}+2\left(c_{1}-c_{2}\right)^{2}+\left(d_{1}-d_{2}\right)^{2}}{6},} \\
& d_{H}(\tilde{x}, \tilde{y})=\frac{\left|a_{1}-a_{2}\right|+\left|b_{1}-b_{2}\right|+\left|c_{1}-c_{2}\right|+\left|d_{1}-d_{2}\right|}{6} .
\end{aligned}
$$

\subsection{Steps of the Ordinary Fuzzy CODAS Method}

The steps of the ordinary fuzzy CODAS method are given as below:

Step 1. Construct the fuzzy decision-making matrix $\left.\left(\tilde{X}_{l}\right)\right)$ of each decision maker and compute the average fuzzy decision matrix $(\tilde{X}))$ :

$$
\begin{gathered}
\tilde{X}_{l}\left[\tilde{x}_{i j l}\right]_{n \times m}=\left[\begin{array}{ccc}
\tilde{x}_{11 l} & \cdots & \tilde{x}_{1 m l} \\
\vdots & \ddots & \vdots \\
\tilde{x}_{n 1 l} & \cdots & \tilde{x}_{n m l}
\end{array}\right], \\
\tilde{X}\left[\tilde{x}_{i j}\right]_{n \times m}=\left[\begin{array}{ccc}
\tilde{x}_{11} & \cdots & \tilde{x}_{1 m} \\
\vdots & \ddots & \vdots \\
\tilde{x}_{n 1} & \cdots & \tilde{x}_{n m}
\end{array}\right], \\
\tilde{x}_{i j}=\frac{\bigoplus_{l=1}^{q} \tilde{x}_{i j l}}{q}
\end{gathered}
$$


where $\tilde{x}_{i j l}$ denotes the fuzzy evaluation score of $i$ th $(i \in\{1,2, \ldots, n\})$ alternative with respect to $j$ th criterion $(j \in\{1,2, \ldots, m\})$ and $l$ th $(l \in\{1,2, \ldots, q\})$ decision maker, and $\tilde{x}_{i j}$ shows the average fuzzy score of $i$ th alternative with respect to $j$ th criterion.

Step 2. Obtain the fuzzy weight of each criterion $\tilde{w}_{j}$ ) from each decision maker:

$$
\begin{aligned}
& \tilde{W}_{l}=\left[\tilde{w}_{j l}\right]_{1 \times m}, \\
& \tilde{W}=\left[\tilde{w}_{j}\right]_{1 \times m}, \\
& \tilde{w}_{j}=\frac{\oplus_{l=1}^{q} \tilde{x}_{j l}}{q},
\end{aligned}
$$

where $\tilde{w}_{j l}$ denotes the fuzzy weight of $j$ th criterion $(j \in\{1,2, \ldots, m\})$ with respect to $l$ th decision maker $(l \in\{1,2, \ldots, q\})$, and $\tilde{w}_{j}$ shows the average fuzzy weight of $j$ th criterion.

Step 3. Determine fuzzy normalized decision matrix $\tilde{N}$ :

$$
\begin{aligned}
& \tilde{N}=\left[\tilde{n}_{i j}\right]_{n \times m}, \\
& \tilde{n}_{i j}= \begin{cases}\frac{\tilde{x}_{i j}}{\max _{i} \mathfrak{H}\left(\tilde{x}_{i j)}\right)} & \text { if } j \in B, \\
1-\frac{\tilde{x}_{x_{j}}}{\max _{i} \mathfrak{H}\left(\tilde{x}_{i j}\right)} & \text { if } j \in C,\end{cases}
\end{aligned}
$$

where $B$ and $C$ represent the sets of benefit and cost criteria, respectively, and $\tilde{n}_{i j}$ denotes the normalized fuzzy scores and $\mathfrak{H}\left(\tilde{x}_{i j}\right)$ is calculated by Eq. (2).

Step 4. Calculate the fuzzy weighted normalized decision matrix $(\tilde{R})$ :

$$
\begin{aligned}
& \tilde{R}=\left[\tilde{r}_{i j}\right]_{n \times m}, \\
& \tilde{r}_{i j}=\tilde{w}_{j} \otimes \tilde{n}_{i j},
\end{aligned}
$$

where $\tilde{w}_{j}$ denotes the fuzzy weight of $j$ th criterion, and $0<\mathfrak{H}\left(\tilde{w}_{j}\right)<1$.

Step 5. Determine the fuzzy negative ideal solution $(\widetilde{N S})$ :

$$
\begin{aligned}
\widetilde{N S} & =\left[\widetilde{n s}_{j}\right]_{1 \times m}, \\
\tilde{n s}_{j} & =\min _{i} \tilde{r}_{i j},
\end{aligned}
$$

where $\min _{i} \tilde{r}_{i j}=\left\{\tilde{r}_{i j} \mid \mathfrak{H}\left(\tilde{r}_{i j}\right)=\min _{i}\left(\mathfrak{H}\left(\tilde{r}_{i j}\right)\right), k \in\{1,2, \ldots, n\}\right\}$.

Step 6. Calculate the weighted Euclidean Distance $\left(E D_{i}\right)$ and weighted Hamming Distance $H D_{i}$ of alternatives from the fuzzy negative ideal solution as given by Eqs. (3) 
and (4):

$$
\begin{aligned}
& E D_{i}=\sum_{j=1}^{m} d_{E}\left(\tilde{r}_{i j}, \tilde{n s}_{j}\right), \\
& H D_{i}=\sum_{j=1}^{m} d_{D}\left(\tilde{r}_{i j}, \tilde{n s}_{j}\right) .
\end{aligned}
$$

Step 7. Determine the relative assessment matrix (RA):

$$
\begin{aligned}
& R A=\left[p_{i k}\right]_{n \times n}, \\
& p_{i k}=\left(E D_{i}-E D_{k}\right)+\left(t\left(E D_{i}-E D_{k}\right)\left(H D_{i}-H D_{k}\right)\right),
\end{aligned}
$$

where $k \in\{1,2, \ldots, n\}$ and $t$ is a threshold function that is defined as follows:

$$
t(x)= \begin{cases}1 & \text { if }|x| \geqslant \theta, \\ 0 & \text { if }|x|<\theta .\end{cases}
$$

The threshold parameter $(\theta)$ of this function can be set by decision maker. In this study, we used $\theta=0.02$ in our calculations by considering the proposed method and the one proposed bydel Moral et al. (2018) which presents how the use of different aggregation operators affects the level of consensus.

Step 8. Calculate the assessment score $\left(A S_{i}\right)$ of each alternative:

$$
A S_{i}=\sum_{k=1}^{n} p_{i k}
$$

Step 9. Rank the alternatives according to the decreasing values of assessment scores and select the alternative with the maximum assessment score.

\section{A Novel Hesitant Fuzzy CODAS Method}

In this section, we firstly give basic definitions and operations on hesitant fuzzy sets and then present the steps of our proposed hesitant fuzzy CODAS method.

\subsection{Preliminaries: Hesitant Fuzzy Sets}

Hesitant fuzzy sets (HFS), initially developed by Torra (2010) are the extensions of regular fuzzy sets which handle the situations where a set of values are possible for the membership of a single element (Rodriguez et al., 2012). Torra (2010) defined hesitant fuzzy sets as follows: let $X$ be a fixed set. A hesitant fuzzy set (HFS) on $X$ is as follows:

$$
E=\left\{\left\langle x, h_{E}(x)\right\rangle \mid x \in X\right\},
$$


where $h_{E}(x)$ is a set of some values in [0,1], denoting the possible membership degrees of the element $x \in X$ to the set $E$. Xu and Xia (2011a) called $h=h_{E}(x)$ as a hesitant fuzzy element (HFE).

Some basic definitions about hesitant sets are given in the following (Torra, 2010);

$$
\begin{aligned}
& \lambda h=U_{\gamma \in h}\left\{1-(1-\gamma)^{\lambda}\right\}, \\
& h_{1} \oplus h_{2}=U_{\gamma_{1} \in h_{1}, \gamma_{2} \in h_{2}}\left\{\gamma_{1}+\gamma_{2}-\gamma_{1} \gamma_{2}\right\}, \\
& h_{1} \otimes h_{2}=U_{\gamma_{1} \in h_{1}, \gamma_{2} \in h_{2}}\left\{\gamma_{1} \gamma_{2}\right\} .
\end{aligned}
$$

In the scope of this study, one of the most important operations is finding the distance between two HFEs. The literature provides different approaches for this purpose. Xu and Xia (2011b) defined the hesitant Euclidean distance as in Eq. (26):

$$
d_{1}\left(h_{1}, h_{2}\right)=\sqrt{\frac{1}{l} \sum_{i=1}^{l}\left|h_{1_{\sigma(i)}}-h_{2_{\sigma(i)}}\right|^{2}} .
$$

Xu and Xia (2011b) proposed Hamming distance measure as in Eq. (27):

$$
d_{1}\left(h_{1}, h_{2}\right)=\frac{1}{l} \sum_{i=1}^{l}\left|h_{1_{\sigma(i)}}-h_{2_{\sigma(i)}}\right|,
$$

where $h_{1}, h_{2}$ are HFEs and $l$ is the number of elements in a HFE, which is called length.

\subsection{Steps of HF-CODAS}

The steps of the hesitant fuzzy CODAS method are given as below:

Step 1. Construct the initial fuzzy decision matrix $\tilde{I}$ by using Table 1 and the fuzzy decision matrix $\tilde{D})$ :

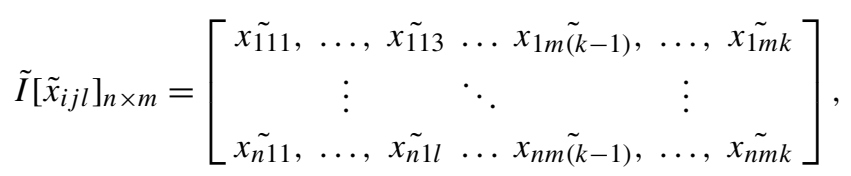

where $\tilde{x_{i j l}}$ represents the $l$ th $(l=1, \ldots, k)$ score value of the $i$ th $(i=1, \ldots, n)$ alternative with respect to $j$ th, $(j=1, \ldots, m)$ criterion.

Before constructing the fuzzy decision matrix, the maximum number of the membership functions for an alternative is determined as a threshold value in the initial decision matrix (see in Eq. (28)). If any score of an alternative is lower than the threshold value, the smallest membership degree of this alternative is assigned to the same alternative as a new membership degree until the value of membership degree equals the threshold value. 
Residential Construction Site Selection Through Interval-Valued Hesitant Fuzzy CODAS 697

Table 1

Scale for scoring values.

\begin{tabular}{ll}
\hline Linguistic terms & Membership function \\
\hline Unimportant - UI & {$[\tau, 1.8]$} \\
Very Poor - VP & {$[0.9,2.7]$} \\
Poor - P & {$[1.8,3.6]$} \\
Medium Poor - MP & {$[2.7,4.5]$} \\
Fair - F & {$[3.6,5.4]$} \\
Medium Good - MG & {$[4.5,6.3]$} \\
Good - G & {$[5.4,7.2]$} \\
Very Good - VG & {$[6.3,8.1]$} \\
Superior - SP & {$[7.2,9]$} \\
$\tau$ is a very small number close to 0. & \\
\hline
\end{tabular}

This procedure is performed for each criterion of each alternative and thus the decision matrix is established as given in Eq. (29).

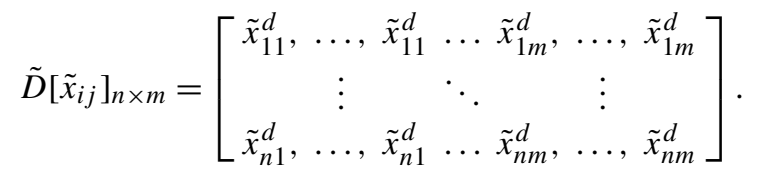

Step 2. Determine fuzzy normalized decision matrix $(\tilde{N})$ :

$$
\begin{aligned}
& \tilde{N}=\left[\tilde{x}_{i j l}^{d, n}\right]_{n \times m}, \\
& x_{\text {lower }_{i j l}}^{d, n}= \begin{cases}\frac{x_{\text {lower }_{i j l}}^{d, n}}{\max _{j} \tilde{x}_{i j l}^{d, n}} & \text { if } j \in B, \\
\frac{\min _{j} \tilde{x}_{i j l}^{d, n}}{d, n} & \text { if } j \in C,\end{cases} \\
& \underset{\text { upper }_{i j l}}{d, n}= \begin{cases}\frac{x_{\text {upper }_{i j l}, n}}{\max _{j} \tilde{x}_{i j l l}^{d, n}} & \text { if } j \in B, \\
\frac{\min _{j} \tilde{x}_{i j l}^{d, n}}{d, n} & \text { if } j \in C, \\
x_{\text {lower }_{i j l}} & \text { if }\end{cases}
\end{aligned}
$$

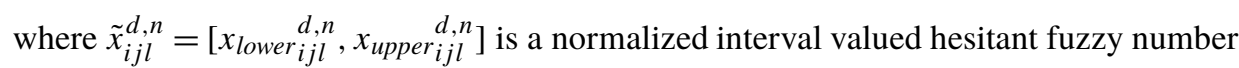
in the decision matrix.

Step 3. Calculate the fuzzy weighted normalized decision matrix $\tilde{R}$ :

$$
\begin{aligned}
& \tilde{R}=\left[\tilde{r}_{i j l}\right]_{n \times m}, \\
& \tilde{r}_{i j l}=\tilde{w}_{j} \otimes \tilde{x}_{i j l}^{d, n},
\end{aligned}
$$

where $w_{j}$ denotes the weight of $j$ th criterion. 
Step 4. Determine the fuzzy negative ideal solution $\widetilde{N S}$ :

$$
\begin{aligned}
& \widetilde{N S}=\left[\tilde{n s}_{j l}\right]_{1 \times m}, \\
& \tilde{n s}_{j}=\min _{i} \tilde{r}_{i j l},
\end{aligned}
$$

where $\min _{i} \tilde{r}_{i j l}=\left\{\tilde{r}_{i j} \mid \mathfrak{H}\left(\tilde{r}_{i j l}\right)=\min _{i}\left(\mathfrak{H}\left(\tilde{r}_{i j l}\right)\right), k \in\{1,2, \ldots, n\}\right\}$.

Step 5. Calculate the fuzzy weighted Euclidean Distance $\left(E D_{i}\right)$ and fuzzy weighted Hamming Distance $\left(H D_{i}\right)$ of alternatives from the fuzzy negative ideal solution:

$$
\begin{aligned}
E D_{i} & =\sum_{j=1}^{m} d_{E}\left(\tilde{r}_{i j l}, \tilde{n s}_{j}\right), \\
H D_{i} & =\sum_{j=1}^{m} d_{D}\left(\tilde{r}_{i j l}, \tilde{n s}_{j}\right) .
\end{aligned}
$$

Step 6. Determine the relative assessment matrix (RA) using Eqs. (19), (20), and (21).

Step 7. Calculate the assessment score $\left(A S_{i}\right)$ of each alternative using Eq. (22).

Step 8. Rank the alternatives according to the decreasing values of assessment scores and select the alternative with maximum assessment score.

The flowchart of the proposed methodology is given in Fig. 1.

\section{Application}

A council consisting of Metropolitan Municipality Directors, Housing Development Administration and Contractors' representatives would like to determine the location of a residential which has 10,000 residences to be built in the city of Istanbul. The council determined 8 alternative construction sites whose locations are indicated in Fig. 2. The evaluation factors consist of 4 main criteria and 14 sub criteria. The aim is to find the best alternative for the residential construction site based on the pre-determined criteria with respect to the council's opinions. The weights of the criteria are obtained by hesitant fuzzy AHP (Tuysuz and Simsek, 2017). These weights are used in the proposed hesitant fuzzy CODAS to obtain the weighted normalized decision matrix. The results of the integrated methodology are verified with the sensitivity analysis. A comparative analysis is also conducted to show the validation of the proposed method.

\subsection{Problem Definition}

The contractors agreed to use a scientific method to determine the most appropriate site from the alternate locations in order to obtain the approval of the residential. They formed an academicians' committee composed of 4 people that would carry out the application. 


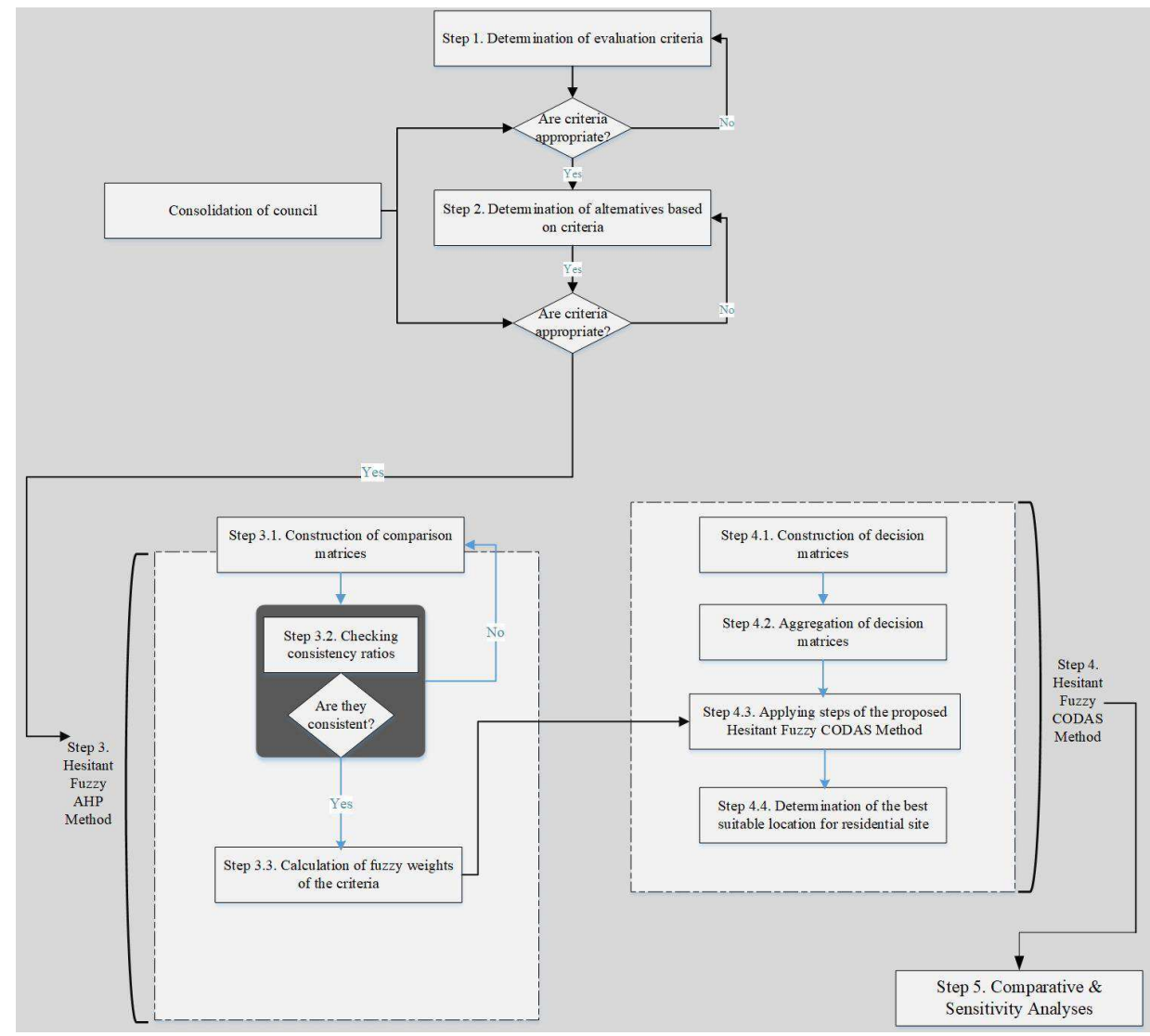

Fig. 1. Flowchart of the application.

Table 2

Determined criteria for the application.

\begin{tabular}{llll}
\hline Social & Attractiveness of land & Economic & Price \\
Criteria & Population characteristics & Criteria & Infrastructure cost \\
& Distance from historical sites & & Construction cost \\
& Distance from other residential areas & & Slope of the land \\
Environmental & Forestland & Technical & Distance from waste production centers \\
Criteria & Agricultural land & Criteria & Distance from high-standard roads \\
& Human and animal habitats & & Distance from industrial areas \\
\hline
\end{tabular}

Since the problem has too many criteria and alternatives, the committee has decided to use some MCDM methods including our integrated methodology for the solution of this problem. In our integrated methodology, the weights of the criteria are determined by hesitant fuzzy AHP and then, the proposed hesitant fuzzy CODAS method is applied to obtain the best residential construction site. The determined criteria for implementation are given in Table 2. 


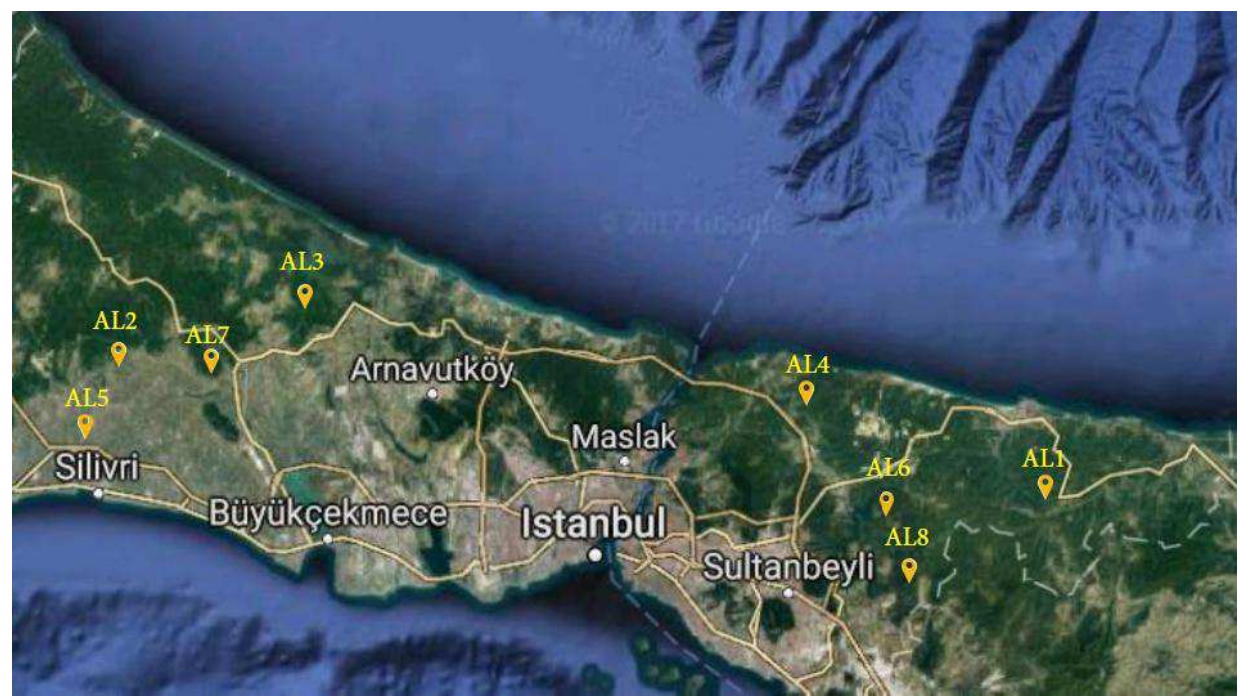

Fig. 2. Location of alternative residential construction sites.

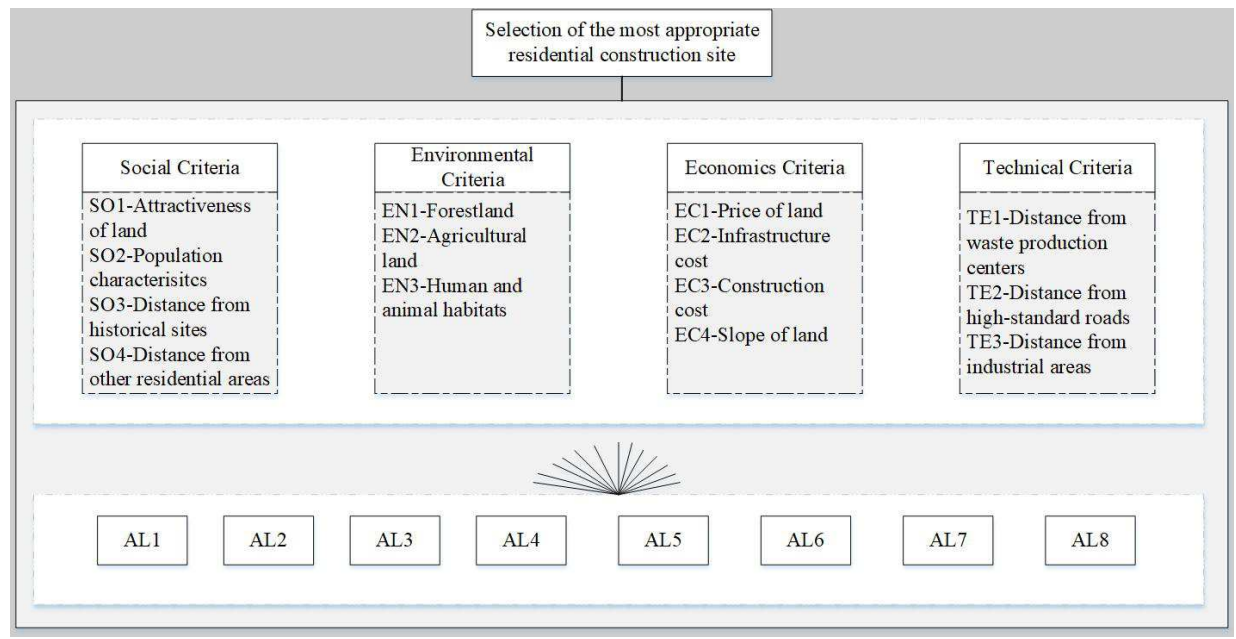

Fig. 3. Hierarchy of the application.

The hierarchy involving the specified criteria and alternatives is given in Fig. 3.

\subsection{Solution of Application}

As the first step of our proposed hesitant fuzzy CODAS method, the initial decision matrix involving linguistic assessments is constructed in Table 3. In this table, the committee can assign different linguistic evaluations for each criterion. The number of these evaluations may change from one to four since the hesitant fuzzy approach requires it. The hyphens 
in the table indicate that a member of the committee did not prefer making an evaluation for the related alternative with respect to the considered criterion.

Secondly, the initial decision matrix is converted to the decision matrix with corresponding numerical membership degrees. The decision matrix is constructed in Table 4. After this point of the method, we partially present the normalized decision matrix (Table 5) and weighted normalized decision matrix (Table 6) because of the space constraints.

As the next step, we calculate the negative-ideal solution by using Eq. (35). The negative solution is found as $(\langle[0.016,0.032],[0.005,0.019],[0.005,0.019],[0.007,0.026]\rangle$, $\langle[0.034,0.06],[0.009,0.031],[0.012,0.046],[0.012,0.046]\rangle, \quad\langle[0.062,0.111],[0.031$, 0.062], [0.026, 0.064], [0.012, 0.043] $\rangle,\langle[0.009,0.018],[0.003,0.011],[0.003,0.013]$, $[0.003,0.013]\rangle,\langle[0.023,0.023],[0.028,0.039],[0.023,0.034],[0.013,0.02]\rangle,\langle[0.065$, 0.092], [0.032, 0.045], [0.021, 0.032], [0.002, 0.003] , $\langle[0.052,0.071],[0.017,0.024]$, [0.024, 0.037], [0.029, 0.052],$\quad\langle[0.032,0.044],[0.02,0.027],[0.011,0.015],[0.015$, $0.023]\rangle,\langle[0.101,0.152],[0.06,0.062],[0.033,0.052],[0.018,0.021]\rangle,\langle[0.085,0.12]$, [0.02, 0.027], [0.023, 0.033], [0.027, 0.043] $\rangle,\langle[0.013,0.019],[0.006,0.008],[0.012$, 0.025], [0.005, 0.009]〉, $\langle[0.027,0.041],[0.004,0.005],[0.004,0.006],[0.005,0.007]\rangle$, $\langle[0.022,0.032],[0.01,0.013],[0.006,0.009],[0.006,0.009]\rangle, \quad\langle[0.074,0.105],[0.06$, 0.087], [0.017, 0.024], [0.002, 0.002])).

Then, Euclidean and Hamming distances to negative-ideal solution are calculated as in Table 7.

At the final step, the relative assessment matrix is constructed, and scores are calculated (see Table 8).

The results indicate that AL4 is the best alternative for construction site. The ranking of alternative sites is as follows: $A L 4>A L 1>A L 3>A L 8>A L 5>A L 6>A L 7>$ AL2.

\subsection{Comparison with Ordinary Fuzzy CODAS and Hesitant TOPSIS Methods}

In this sub-section, we compare our novel hesitant CODAS method with the ordinary fuzzy CODAS method. The membership values in the decision matrix of hesitant fuzzy CODAS are aggregated and thus, unified interval-valued fuzzy numbers are obtained to apply ordinary fuzzy CODAS method. Since trapezoidal fuzzy numbers are used in ordinary fuzzy CODAS method proposed by Keshavarz Ghorabaee et al. (2017), interval-valued fuzzy numbers are converted to trapezoidal fuzzy numbers. For instance, $(3.15,4.95)$ is converted to $(3.15,3.15,4.95,4.95)$. The aggregated decision matrix is given in Table 9 .

The results of the ordinary fuzzy CODAS method are given in Table 10.

We apply different decision matrices since the different rankings are obtained from the ordinary fuzzy CODAS method. In most of the cases, both methods produced the same results. However, when the fuzziness is increased, our proposed method overcomes the disadvantages of the ordinary fuzzy sets and gives better solutions than the ordinary fuzzy CODAS method.

Secondly, we also compare our proposed method with hesitant fuzzy TOPSIS (Xu and Zhang, 2013). We used the same weighted normalized decision matrix since both methods 
Table 3

Decision matrix with linguistic terms.

\begin{tabular}{|c|c|c|c|c|c|c|c|c|c|c|c|c|c|c|c|c|c|c|c|c|c|c|c|c|c|c|c|c|}
\hline \multirow[b]{2}{*}{ AL1 } & \multicolumn{4}{|c|}{ SO1 } & \multicolumn{4}{|c|}{$\mathrm{SO} 2$} & \multicolumn{4}{|c|}{$\mathrm{SO} 3$} & \multicolumn{4}{|c|}{$\mathrm{SO} 4$} & \multicolumn{4}{|c|}{ EN1 } & \multicolumn{4}{|c|}{ EN2 } & \multicolumn{4}{|c|}{ EN3 } \\
\hline & MG & VP & - & VG & MG & - & $\mathrm{F}$ & MG & MG & G & MG & MG & VG & - & MG & $\mathrm{F}$ & $\mathrm{F}$ & G & $\mathrm{F}$ & $\mathrm{F}$ & $\mathrm{F}$ & $P$ & - & VP & $\mathrm{P}$ & MP & VP & VP \\
\hline AL2 & - & MP & VP & VP & VG & MP & - & MG & G & MP & $\mathrm{F}$ & VG & $\mathrm{F}$ & G & G & MP & - & $\mathrm{F}$ & - & MP & UI & $\mathrm{F}$ & VG & G & $\mathrm{F}$ & MG & G & MP \\
\hline L3 & $\mathrm{P}$ & VG & MP & $\mathrm{F}$ & $\mathrm{F}$ & MG & G & - & VG & MP & - & $\mathrm{P}$ & - & MP & VP & - & $P$ & MG & - & G & - & VP & MP & MG & G & MP & MP & $\mathrm{F}$ \\
\hline L4 & $\mathrm{P}$ & VG & - & VP & MG & - & $\mathrm{F}$ & VG & VG & $\mathrm{F}$ & MG & VG & - & G & VG & MG & VP & $\mathrm{P}$ & G & G & MG & - & VG & $\mathrm{F}$ & $P$ & VG & MP & G \\
\hline L5 & VG & MG & SP & VG & G & F & MP & SP & G & VP & $\mathrm{F}$ & $P$ & MG & - & VG & VP & MP & VP & G & MG & MP & VG & MG & MP & - & $\mathrm{P}$ & G & $\mathrm{F}$ \\
\hline AL6 & VG & VP & G & $\mathrm{P}$ & MG & $\mathrm{F}$ & G & MP & MG & $\mathrm{F}$ & MP & $\mathrm{P}$ & - & G & G & MP & VG & $\mathrm{F}$ & VG & MG & MG & VG & MP & MP & - & - & VP & MG \\
\hline L7 & MG & $\mathrm{P}$ & F & VG & $\mathrm{F}$ & VG & MP & G & - & G & G & $\mathrm{P}$ & VG & VP & MG & MG & $\mathrm{F}$ & G & $\mathrm{F}$ & MP & $P$ & MP & MG & F & VP & VP & G & $\mathrm{P}$ \\
\hline \multirow[t]{2}{*}{ AL8 } & $\mathrm{F}$ & VP & F & - & F & VP & - & VP & P & $\mathrm{P}$ & G & VG & MG & VG & $\mathrm{F}$ & VP & MG & - & $\mathrm{P}$ & MP & VG & - & $\mathrm{F}$ & G & $\mathrm{P}$ & $\mathrm{P}$ & G & G \\
\hline & \multicolumn{4}{|c|}{ EC1 } & \multicolumn{4}{|c|}{ EC2 } & \multicolumn{4}{|c|}{ EC3 } & \multicolumn{4}{|c|}{ EC4 } & \multicolumn{4}{|c|}{ TE1 } & \multicolumn{4}{|c|}{ TE2 } & \multicolumn{4}{|c|}{ TE3 } \\
\hline AL1 & $P$ & VP & - & $\mathrm{F}$ & MG & - & G & $\mathrm{F}$ & $\mathrm{P}$ & G & MP & $P$ & $\mathrm{P}$ & VG & MG & $\mathrm{P}$ & G & VG & VP & VG & VG & - & - & MG & G & VP & MG & UI \\
\hline AL2 & MP & MG & $\mathrm{P}$ & MG & G & G & MG & VG & MP & MP & $\mathrm{F}$ & VG & MG & MP & G & MP & VP & VP & MG & $P$ & $P$ & VG & $P$ & - & - & VG & G & - \\
\hline $\mathbf{L 3}$ & G & G & MP & VG & $\mathrm{F}$ & G & MP & $\mathrm{F}$ & VP & G & G & MG & VG & $\mathrm{P}$ & VG & $\mathrm{P}$ & MG & $\mathrm{P}$ & VP & MG & MG & VP & $\mathrm{F}$ & VP & MP & G & - & VP \\
\hline L4 & MP & $\mathrm{P}$ & - & G & VP & $\mathrm{P}$ & VG & MG & $\mathrm{F}$ & - & $\mathrm{F}$ & MG & MP & - & $\mathrm{P}$ & G & VP & VP & MG & MP & MP & VP & MP & $\mathrm{F}$ & $\mathrm{F}$ & $P$ & P & MP \\
\hline AL5 & $\mathrm{P}$ & MP & - & $\mathrm{P}$ & MP & MG & - & G & $\mathrm{F}$ & $\mathrm{F}$ & $\mathrm{F}$ & MG & $\mathrm{F}$ & MP & $\mathrm{P}$ & $\mathrm{F}$ & G & MG & VG & G & $\mathrm{F}$ & MG & G & $\mathrm{F}$ & MP & MP & VP & G \\
\hline AL6 & VP & VG & F & MP & MP & G & $\mathrm{F}$ & - & VP & - & $\mathrm{F}$ & - & VG & $\mathrm{P}$ & $\mathrm{P}$ & - & MG & G & MG & $\mathrm{F}$ & VG & MG & VP & MP & VP & $\mathrm{F}$ & MP & G \\
\hline AL7 & VG & MG & $\mathrm{F}$ & VG & $\mathrm{P}$ & MG & - & MP & $\mathrm{P}$ & VG & $\mathrm{F}$ & $\mathrm{P}$ & MP & - & $\mathrm{F}$ & $P$ & VG & $\mathrm{P}$ & - & $P$ & MP & VG & VG & P & G & MP & G & MP \\
\hline AL8 & $P$ & G & - & - & VG & VP & F & G & MG & MP & $\mathrm{F}$ & VP & MG & VP & VG & $\mathrm{P}$ & VP & G & - & VP & VG & F & MP & G & UI & VP & VG & G \\
\hline
\end{tabular}


Table 4

Decision matrix with membership degrees.

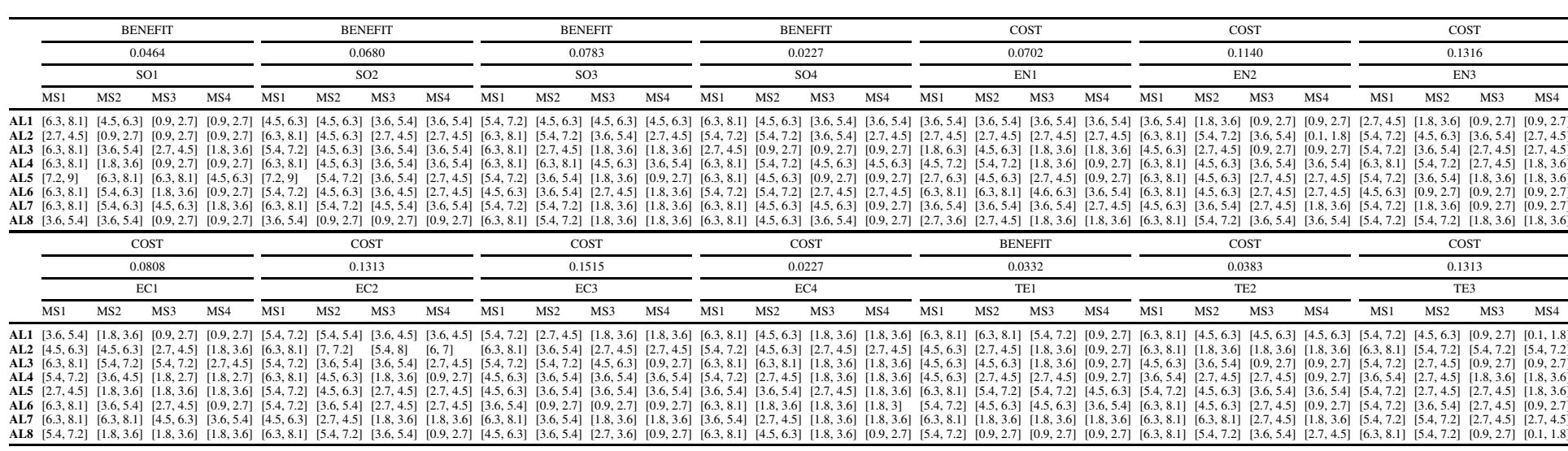


Table 5

Normalized decision matrix.

\begin{tabular}{lcccccccc}
\hline Type & \multicolumn{9}{c}{ BENEFIT } \\
Weight & \multicolumn{3}{c}{0.0464} \\
\hline Criteria & \multicolumn{3}{c}{ SO1 } & \multicolumn{3}{c}{ COST } \\
\hline Membership & MS1 & MS2 & MS3 & MS4 & MS1 & MS2 & MS3 & MS4 \\
\hline AL1 & {$[0.7,0.9]$} & {$[0.56,0.78]$} & {$[0.11,0.33]$} & {$[0.14,0.43]$} & {$[0.5,0.67]$} & {$[0.43,0.6]$} & {$[0.33,1]$} & {$[0.06,1]$} \\
\hline AL2 & {$[0.3,0.5]$} & {$[0.11,0.33]$} & {$[0.11,0.33]$} & {$[0.14,0.43]$} & {$[0.44,0.57]$} & {$[0.38,0.5]$} & {$[0.13,0.17]$} & {$[0.01,0.02]$} \\
AL3 & {$[0.7,0.9]$} & {$[0.44,0.67]$} & {$[0.33,0.56]$} & {$[0.29,0.57]$} & {$[0.5,0.67]$} & {$[0.6,1]$} & {$[0.33,1]$} & {$[0.04,0.11]$} \\
AL4 & {$[0.7,0.9]$} & {$[0.22,0.44]$} & {$[0.11,0.33]$} & {$[0.14,0.43]$} & {$[0.67,1]$} & {$[0.6,1]$} & {$[0.25,0.5]$} & {$[0.03,0.06]$} \\
AL5 & {$[0.8,1]$} & {$[0.78,1]$} & {$[0.78,1]$} & {$[0.71,1]$} & {$[0.5,0.67]$} & {$[0.6,1]$} & {$[0.2,0.33]$} & {$[0.03,0.06]$} \\
AL6 & {$[0.7,0.9]$} & {$[0.67,0.78]$} & {$[0.22,0.44]$} & {$[0.14,0.43]$} & {$[0.5,0.67]$} & {$[0.5,0.75]$} & {$[0.2,0.33]$} & {$[0.04,0.11]$} \\
AL7 & {$[0.7,0.9]$} & {$[0.67,0.78]$} & {$[0.56,0.78]$} & {$[0.29,0.57]$} & {$[0.5,0.67]$} & {$[0.38,0.5]$} & {$[0.2,0.33]$} & {$[0.02,0.04]$} \\
AL8 & {$[0.4,0.6]$} & {$[0.44,0.67]$} & {$[0.11,0.33]$} & {$[0.14,0.43]$} & {$[0.44,0.57]$} & {$[0.38,0.5]$} & {$[0.33,1]$} & {$[0.06,1]$} \\
\hline
\end{tabular}

Table 6

Weighted normalized decision matrix.

\begin{tabular}{|c|c|c|c|c|c|c|c|c|}
\hline Type & \multicolumn{4}{|c|}{ BENEFIT } & \multicolumn{4}{|c|}{ COST } \\
\hline Weight & \multicolumn{4}{|c|}{0.0464} & \multicolumn{4}{|c|}{0.1313} \\
\hline Criteria & \multicolumn{4}{|c|}{ SO1 } & \multicolumn{4}{|c|}{ TE3 } \\
\hline Membership & MS1 & MS2 & MS3 & MS4 & MS1 & MS2 & MS3 & MS4 \\
\hline$\overline{A L 1}$ & {$[0.054,0.101]$} & {$[0.037,0.067]$} & {$[0.005,0.019]$} & {$[0.007,0.026]$} & {$[0.052,1]$} & {$[0.052,1]$} & {$[0.054,0.106]$} & {$[0.054,1]$} \\
\hline$\overline{\text { AL2 }}$ & {$[0.016,0.032]$} & {$[0.005,0.019]$} & {$[0.005,0.019]$} & {$[0.007,0.026]$} & {$[0.024,0.037]$} & {$[0.029,0.052]$} & {$[0.044,0.071]$} & {$[0.027,0.04]$} \\
\hline AL3 & {$[0.054,0.101]$} & {$[0.027,0.05]$} & {$[0.019,0.037]$} & {$[0.015,0.039]$} & {$[0.029,0.052]$} & {$[0.029,0.052]$} & {$[0.032,0.044]$} & {$[0.023,0.032]$} \\
\hline AL4 & {$[0.054,0.101]$} & {$[0.012,0.027]$} & {$[0.005,0.019]$} & {$[0.007,0.026]$} & {$[0.029,0.052]$} & {$[0.037,0.087]$} & {$[0.037,0.054]$} & {$[0.04,0.054]$} \\
\hline AL5 & {$[0.072,1]$} & {$[0.067,1]$} & {$[0.067,1]$} & {$[0.056,1]$} & {$[0.037,0.087]$} & {$[0.037,0.087]$} & {$[0.071,1]$} & {$[0.054,1]$} \\
\hline AL6 & {$[0.054,0.101]$} & {$[0.05,0.067]$} & {$[0.012,0.027]$} & {$[0.007,0.026]$} & {$[0.052,1]$} & {$[0.052,1]$} & {$[0.032,0.044]$} & {$[0.032,0.054]$} \\
\hline AL7 & {$[0.054,0.101]$} & {$[0.05,0.067]$} & {$[0.037,0.067]$} & {$[0.015,0.039]$} & {$[0.052,1]$} & {$[0.052,1]$} & {$[0.032,0.044]$} & {$[0.02,0.027]$} \\
\hline AL8 & {$[0.023,0.042]$} & {$[0.027,0.05]$} & {$[0.005,0.019]$} & {$[0.007,0.026]$} & {$[0.037,0.087]$} & {$[0.037,0.087]$} & {$[0.037,0.054]$} & {$[0.054,1]$} \\
\hline
\end{tabular}

Table 7

Euclidean and Hamming distances to negative-ideal solution.

\begin{tabular}{llllllllllllllll}
\hline & & SO1 & SO2 & SO3 & SO4 & EN1 & EN2 & EN3 & EC1 & EC2 & EC3 & EC4 & TE1 & TE2 & TE3 \\
\hline Euclidean & AL1 & 0.0347 & 0.4797 & 0.4755 & 0.3479 & 0.0242 & 0.5786 & 0.5808 & 0.5999 & 0.0311 & 0.0367 & 0.3449 & 0.3510 & 0.0026 & 0.4939 \\
distance & AL2 & 0.0000 & 0.0652 & 0.3193 & 0.3504 & 0.3414 & 0.3524 & 0.0067 & 0.0178 & 0.0000 & 0.0133 & 0.0026 & 0.4881 & 0.3492 & 0.0000 \\
& AL3 & 0.0325 & 0.4800 & 0.3149 & 0.0000 & 0.5961 & 0.3445 & 0.0100 & 0.0041 & 0.0475 & 0.3389 & 0.3449 & 0.4881 & 0.4959 & 0.4733 \\
& AL4 & 0.0283 & 0.4808 & 0.5671 & 0.6978 & 0.4866 & 0.0045 & 0.0139 & 0.0241 & 0.4827 & 0.0368 & 0.3449 & 0.4881 & 0.4901 & 0.4535 \\
& AL5 & 0.6916 & 0.5865 & 0.0202 & 0.3475 & 0.3479 & 0.0066 & 0.0238 & 0.4830 & 0.0439 & 0.0368 & 0.3469 & 0.0004 & 0.0046 & 0.3237 \\
& AL6 & 0.0366 & 0.0611 & 0.0174 & 0.3503 & 0.0000 & 0.0066 & 0.5899 & 0.3457 & 0.0551 & 0.6689 & 0.4920 & 0.0065 & 0.3506 & 0.0338 \\
& AL7 & 0.0421 & 0.5903 & 0.0436 & 0.4927 & 0.0244 & 0.0312 & 0.4785 & 0.0013 & 0.5603 & 0.0327 & 0.4892 & 0.0106 & 0.0070 & 0.0156 \\
& AL8 & 0.0140 & 0.0000 & 0.3173 & 0.3477 & 0.4828 & 0.0000 & 0.0232 & 0.3448 & 0.3467 & 0.3408 & 0.4916 & 0.6086 & 0.0030 & 0.4937 \\
Hamming & AL1 & 0.1532 & 0.5260 & 0.5232 & 0.3796 & 0.1322 & 0.6087 & 0.6160 & 0.6218 & 0.1673 & 0.1773 & 0.3524 & 0.3537 & 0.0350 & 0.5115 \\
distance & AL2 & 0.0000 & 0.2474 & 0.4005 & 0.3764 & 0.3808 & 0.3538 & 0.0633 & 0.1245 & 0.0000 & 0.1013 & 0.0415 & 0.5010 & 0.3622 & 0.0000 \\
& AL3 & 0.1631 & 0.5306 & 0.3489 & 0.0000 & 0.6136 & 0.3880 & 0.0894 & 0.0510 & 0.1953 & 0.3600 & 0.3513 & 0.4999 & 0.5073 & 0.5044 \\
& AL4 & 0.1234 & 0.5376 & 0.6236 & 0.7113 & 0.5028 & 0.0458 & 0.0891 & 0.1474 & 0.5096 & 0.1446 & 0.3567 & 0.4995 & 0.5044 & 0.5014 \\
& AL5 & 0.7189 & 0.6299 & 0.1132 & 0.3641 & 0.3846 & 0.0668 & 0.1373 & 0.5117 & 0.1925 & 0.1446 & 0.3556 & 0.0135 & 0.0613 & 0.3631 \\
& AL6 & 0.1639 & 0.2388 & 0.1204 & 0.3729 & 0.0000 & 0.0668 & 0.6159 & 0.3639 & 0.2138 & 0.7029 & 0.4989 & 0.0623 & 0.3571 & 0.1597 \\
& AL7 & 0.1943 & 0.6372 & 0.1771 & 0.5090 & 0.1373 & 0.1451 & 0.5086 & 0.0247 & 0.6101 & 0.1505 & 0.5003 & 0.0901 & 0.0635 & 0.1031 \\
& AL8 & 0.0932 & 0.0000 & 0.3744 & 0.3719 & 0.5150 & 0.0000 & 0.1280 & 0.3733 & 0.3694 & 0.3856 & 0.4975 & 0.6155 & 0.0461 & 0.5017 \\
\hline
\end{tabular}

have the same steps to obtain it. The positive ideal solutions of hesitant TOPSIS method are given in Table 11.

The negative ideal solutions of the hesitant TOPSIS method are given in Table 12.

After the calculations, results of the hesitant TOPSIS method are calculated as in Table 13 .

The results of the compared methods are the same. Thus, our proposed model is valid where hesitant fuzzy sets can be used as input data. 
Residential Construction Site Selection Through Interval-Valued Hesitant Fuzzy CODAS 705

Table 8

Relative assessment matrix and assessment scores based on HF-CODAS

\begin{tabular}{lllllllllll}
\hline & AL1 & AL2 & AL3 & AL4 & AL5 & AL6 & AL7 & AL8 & Scores & Rank \\
\hline AL1 & 0 & 4.28 & 0.97 & -0.36 & 2.22 & 2.59 & 2.87 & 1.45 & 14 & 2 \\
AL2 & -4.28 & 0 & -3.31 & -4.64 & -2.06 & -1.69 & -1.41 & -2.83 & -20.2 & 8 \\
AL3 & -0.97 & 3.31 & 0 & -1.32 & 1.25 & 1.62 & 1.9 & 0.49 & 6.29 & 3 \\
AL4 & 0.36 & 4.64 & 1.32 & 0 & 2.58 & 2.94 & 3.23 & 1.81 & 16.9 & 1 \\
AL5 & -2.22 & 2.06 & -1.25 & -2.58 & 0 & 0.37 & 0.65 & -0.77 & -3.73 & 5 \\
AL6 & -2.59 & 1.69 & -1.62 & -2.94 & -0.37 & 0 & 0.28 & -1.13 & -6.68 & 6 \\
AL7 & -2.87 & 1.41 & -1.9 & -3.23 & -0.65 & -0.28 & 0 & -1.42 & -8.93 & 7 \\
AL8 & -1.45 & 2.83 & -0.49 & -1.81 & 0.77 & 1.13 & 1.42 & 0 & 2.39 & 4 \\
\hline
\end{tabular}

Table 9

Decision matrix of ordinary fuzzy CODAS.

\begin{tabular}{llllllll}
\hline & SO1 & SO2 & SO3 & SO4 & EN1 & EN2 & EN3 \\
\hline AL1 & $(3.15,4.95)$ & $(4.05,5.85)$ & $(4.73,6.53)$ & $(4.5,6.3)$ & $(3.6,5.4)$ & $(1.8,3.6)$ & $(1.58,3.38)$ \\
AL2 & $(1.35,3.15)$ & $(4.05,5.85)$ & $(4.5,6.3)$ & $(4.28,6.08)$ & $(2.7,4.5)$ & $(3.85,5.63)$ & $(4.05,5.85)$ \\
AL3 & $(3.6,5.4)$ & $(4.28,6.08)$ & $(3.15,4.95)$ & $(1.35,3.15)$ & $(2.48,4.95)$ & $(2.25,4.05)$ & $(3.6,5.4)$ \\
AL4 & $(2.48,4.28)$ & $(4.5,6.3)$ & $(5.18,6.98)$ & $(5.18,6.98)$ & $(3.15,5.18)$ & $(4.5,6.3)$ & $(4.05,5.85)$ \\
AL5 & $(6.08,7.88)$ & $(4.73,6.53)$ & $(2.93,4.73)$ & $(3.15,4.95)$ & $(2.7,4.95)$ & $(4.05,5.85)$ & $(3.15,4.95)$ \\
AL6 & $(3.6,5.18)$ & $(4.05,5.63)$ & $(3.15,4.95)$ & $(4.05,5.85)$ & $(5.2,6.98)$ & $(4.05,5.85)$ & $(1.8,3.6)$ \\
AL7 & $(4.5,6.08)$ & $(4.95,6.53)$ & $(3.6,5.4)$ & $(4.05,5.85)$ & $(3.38,5.18)$ & $(3.15,4.95)$ & $(2.25,4.05)$ \\
AL8 & $(2.25,4.05)$ & $(1.58,3.38)$ & $(3.83,5.63)$ & $(3.83,5.63)$ & $(2.25,3.83)$ & $(4.73,6.53)$ & $(3.6,5.4)$ \\
\hline & EC1 & EC2 & EC3 & EC4 & TE1 & TE2 & TE3 \\
\hline AL1 & $(1.8,3.6)$ & $(4.5,5.4)$ & $(2.93,4.73)$ & $(3.6,5.4)$ & $(4.73,6.53)$ & $(4.95,6.75)$ & $(2.73,4.5)$ \\
AL2 & $(3.38,5.18)$ & $(6.18,7.58)$ & $(3.83,5.63)$ & $(3.83,5.63)$ & $(2.48,4.28)$ & $(2.93,4.73)$ & $(5.63,7.43)$ \\
AL3 & $(4.95,6.75)$ & $(3.83,5.63)$ & $(4.05,5.85)$ & $(4.05,5.85)$ & $(2.93,4.73)$ & $(2.48,4.28)$ & $(2.48,4.28)$ \\
AL4 & $(3.15,4.28)$ & $(3.38,5.18)$ & $(3.83,5.63)$ & $(2.93,4.73)$ & $(2.7,4.5)$ & $(2.48,4.28)$ & $(2.48,4.28)$ \\
AL5 & $(2.03,3.83)$ & $(3.83,5.63)$ & $(3.83,5.63)$ & $(2.93,4.73)$ & $(5.4,7.2)$ & $(4.28,6.08)$ & $(3.15,4.95)$ \\
AL6 & $(3.38,5.18)$ & $(3.6,5.4)$ & $(1.58,3.38)$ & $(2.93,4.58)$ & $(4.5,6.3)$ & $(3.6,5.4)$ & $(3.15,4.95)$ \\
AL7 & $(5.18,6.98)$ & $(2.7,4.5)$ & $(3.38,5.18)$ & $(2.48,4.28)$ & $(2.93,4.73)$ & $(4.28,6.08)$ & $(4.05,5.85)$ \\
AL8 & $(2.7,4.5)$ & $(4.05,5.85)$ & $(2.93,4.5)$ & $(3.38,5.18)$ & $(2.03,3.83)$ & $(4.5,6.3)$ & $(3.18,4.95)$ \\
\hline
\end{tabular}

Table 10

Relative assessment matrix and assessment scores for ordinary fuzzy CODAS method.

\begin{tabular}{lllllllllll}
\hline & AL1 & AL2 & AL3 & AL4 & AL5 & AL6 & AL7 & AL8 & Scores & Rank \\
\hline AL1 & 0.00 & 0.36 & 0.19 & 0.18 & 0.18 & 0.11 & 0.18 & 0.29 & 1.49 & 1 \\
AL2 & -0.36 & 0.00 & -0.17 & -0.18 & -0.18 & -0.25 & -0.18 & -0.08 & -1.41 & 8 \\
AL3 & -0.19 & 0.17 & 0.00 & 0.00 & -0.01 & -0.08 & 0.00 & 0.10 & -0.01 & 6 \\
AL4 & -0.18 & 0.18 & 0.00 & 0.00 & 0.00 & -0.07 & 0.00 & 0.10 & 0.02 & 5 \\
AL5 & -0.18 & 0.18 & 0.01 & 0.00 & 0.00 & -0.07 & 0.00 & 0.11 & 0.06 & 3 \\
AL6 & -0.11 & 0.25 & 0.08 & 0.07 & 0.07 & 0.00 & 0.07 & 0.17 & 0.59 & 2 \\
AL7 & -0.18 & 0.18 & 0.00 & 0.00 & 0.00 & -0.07 & 0.00 & 0.11 & 0.05 & 4 \\
AL8 & -0.29 & 0.08 & -0.10 & -0.10 & -0.11 & -0.17 & -0.11 & 0.00 & -0.80 & 7 \\
\hline
\end{tabular}

\subsection{Sensitivity Analysis}

One-at-a-time sensitivity analysis based on each criterion is performed to demonstrate the effects of changes on the results. To visualize this analysis, we develop a pattern which is 
Table 11

Positive ideal solutions of hesitant TOPSIS method.

\begin{tabular}{llllllllllllllll}
\hline & SO1 & SO2 & SO3 & SO4 & EN1 & EN2 & EN3 & EC1 & EC2 & EC3 & EC4 & TE1 & TE2 & TE3 & Sum \\
\hline AL1 & 0.671 & 0.448 & 0.433 & 0.585 & 0.674 & 0.349 & 0.323 & 0.316 & 0.63 & 0.635 & 0.603 & 0.602 & 0.695 & 0.494 & 7.46 \\
AL2 & 0.692 & 0.618 & 0.533 & 0.588 & 0.577 & 0.579 & 0.672 & 0.672 & 0.658 & 0.658 & 0.695 & 0.491 & 0.595 & 0.704 & 8.73 \\
AL3 & 0.668 & 0.442 & 0.575 & 0.698 & 0.473 & 0.553 & 0.667 & 0.686 & 0.618 & 0.57 & 0.604 & 0.492 & 0.479 & 0.497 & 8.02 \\
AL4 & 0.678 & 0.431 & 0.304 & 0 & 0.479 & 0.675 & 0.667 & 0.669 & 0.434 & 0.649 & 0.599 & 0.493 & 0.486 & 0.498 & 7.06 \\
AL5 & 0 & 0.313 & 0.648 & 0.598 & 0.569 & 0.673 & 0.655 & 0.473 & 0.619 & 0.649 & 0.601 & 0.697 & 0.693 & 0.609 & 7.8 \\
AL6 & 0.669 & 0.625 & 0.646 & 0.591 & 0.687 & 0.673 & 0.314 & 0.586 & 0.609 & 0 & 0.491 & 0.693 & 0.599 & 0.701 & 7.88 \\
AL7 & 0.659 & 0.302 & 0.63 & 0.485 & 0.669 & 0.656 & 0.457 & 0.688 & 0.323 & 0.644 & 0.49 & 0.688 & 0.692 & 0.703 & 8.09 \\
AL8 & 0.684 & 0.677 & 0.556 & 0.592 & 0.47 & 0.677 & 0.657 & 0.579 & 0.547 & 0.55 & 0.492 & 0.333 & 0.694 & 0.496 & 8 \\
\hline
\end{tabular}

Table 12

Positive ideal solution of hesitant TOPSIS method.

\begin{tabular}{llllllllllllllll}
\hline & SO1 & SO2 & SO3 & SO4 & EN1 & EN2 & EN3 & EC1 & EC2 & EC3 & EC4 & TE1 & TE2 & TE3 & Sum \\
\hline AL1 & 0.035 & 0.48 & 0.476 & 0.348 & 0.021 & 0.579 & 0.581 & 0.6 & 0.032 & 0.037 & 0.345 & 0.351 & 0.003 & 0.499 & 4.39 \\
AL2 & 0 & 0.065 & 0.319 & 0.35 & 0.341 & 0.352 & 0.007 & 0.018 & 0 & 0.013 & 0.003 & 0.488 & 0.349 & 0 & 2.31 \\
AL3 & 0.032 & 0.48 & 0.315 & 0 & 0.486 & 0.345 & 0.01 & 0.004 & 0.048 & 0.339 & 0.345 & 0.488 & 0.496 & 0.498 & 3.88 \\
AL4 & 0.028 & 0.481 & 0.567 & 0.698 & 0.487 & 0.004 & 0.014 & 0.024 & 0.483 & 0.037 & 0.345 & 0.488 & 0.49 & 0.496 & 4.64 \\
AL5 & 0.692 & 0.586 & 0.02 & 0.348 & 0.347 & 0.007 & 0.024 & 0.483 & 0.044 & 0.037 & 0.347 & 0.0004 & 0.005 & 0.351 & 3.29 \\
AL6 & 0.037 & 0.061 & 0.017 & 0.35 & 0 & 0.007 & 0.59 & 0.346 & 0.055 & 0.669 & 0.492 & 0.006 & 0.351 & 0.003 & 2.98 \\
AL7 & 0.042 & 0.59 & 0.044 & 0.493 & 0.023 & 0.031 & 0.479 & 0.001 & 0.56 & 0.033 & 0.489 & 0.011 & 0.007 & 0.001 & 2.8 \\
AL8 & 0.014 & 0 & 0.317 & 0.348 & 0.483 & 0 & 0.023 & 0.345 & 0.347 & 0.341 & 0.492 & 0.609 & 0.003 & 0.499 & 3.82 \\
\hline
\end{tabular}

Table 13

Positive ideal solution of hesitant TOPSIS method.

\begin{tabular}{lllllllll}
\hline & AL1 & AL2 & AL3 & AL4 & AL5 & AL6 & AL7 & AL8 \\
\hline Score & 0.37 & 0.21 & 0.33 & 0.4 & 0.3 & 0.27 & 0.26 & 0.32 \\
Rank & 2 & 8 & 3 & 1 & 5 & 6 & 7 & 4 \\
\hline
\end{tabular}

Table 14

Pattern for the sensitivity analysis.

\begin{tabular}{|c|c|c|c|}
\hline Pattern & Sets with $\mathrm{r}$ & ct to criteria & \\
\hline Test variables & SO1 & $\mathrm{SO} 2$ & TE3 \\
\hline 0.1 & AL4, AL1 & AL4, AL1 & $\mathrm{AL} 4, \mathrm{AL} 1$ \\
\hline 0.2 & $\mathrm{AL} 4, \mathrm{AL} 1$ & AL4, AL1 & $\mathrm{AL} 4, \mathrm{AL} 1$ \\
\hline 0.3 & AL4, AL1 & AL4, AL1 & $\mathrm{AL} 4, \mathrm{AL} 1$ \\
\hline 0.4 & $\mathrm{AL} 4, \mathrm{AL} 1$ & AL4, AL1 & $\mathrm{AL} 4, \mathrm{AL} 1$ \\
\hline 0.5 & AL4, AL1 & AL4, AL1 & $\mathrm{AL} 4, \mathrm{AL} 1$ \\
\hline 0.6 & AL4, AL1 & AL4, AL1 & $\mathrm{AL} 4, \mathrm{AL} 1$ \\
\hline 0.7 & AL4, AL1 & AL4, AL1 & $\mathrm{AL} 4, \mathrm{AL} 1$ \\
\hline 0.8 & AL4, AL1 & AL4, AL1 & AL4, AL1 \\
\hline 0.9 & AL4, AL1 & AL4, AL1 & AL4, AL1 \\
\hline 1.0 & AL4, AL1 & AL4, AL1 & $\mathrm{AL} 4, \mathrm{AL} 1$ \\
\hline
\end{tabular}

given in Table 14. After the changes on weights of the sub-criteria through this pattern, hesitant fuzzy CODAS method operations are re-processed. In Table 14, only the first and second alternatives are presented.

When the results of the sensitivity analyses are examined, it is revealed that criterion SO2 with an interval of $[0.7,1]$ and criterion EC3 with an interval of $[0.7,1]$ affect the results. But they don't affect the rank of the best alternative. This verifies the robustness of the proposed model on the given decision. 


\section{Conclusions}

In today's world, urban cities are getting larger and many residential areas are constructed to supply the demand of housing needs. Residential construction site selection problem is an MCDM problem since it includes many alternatives and criteria which might be tangible and intangible. This study has developed a new hesitant fuzzy MCDM extension of CODAS method aiming at selecting the most suitable construction site location. CODAS method is a useful and efficient distance-based method since it combines the advantages of Euclidean and Hamming distances. It has been applied to the selection problem of the best location site of a residential site in Istanbul. Sensitivity and comparative analyses have been also realized in order to observe the robustness and sensitiveness of the given decisions.

For further research, considered criteria can be extended by adding the citizen opinions and different user sentiments such as social media networks can be included for the assessment process as such studies (Morente-Molinera et al., 2019). Also, we suggest other fuzzy extensions of CODAS method to be developed for comparative purposes. Neutrosophic CODAS method or Pythagorean fuzzy CODAS method are the possible extensions to develop. Types of fuzzy numbers can be also changed in order to obtain the variants of the developed new extensions. Hesitant fuzzy CODAS can be worked with triangular fuzzy numbers, for instance.

\section{References}

Atanassov, K. (1986). Intuitionistic fuzzy sets. Fuzzy Sets and Systems, 20(1), 87-96.

Bagocius, V., Zavadskas, E.K., Turskis, Z. (2014). Selecting a location for a liquefied natural gas terminal in the Eastern Baltic Sea. Transport, 29(1), 69-74.

Bahrani, S., Ebadi, T., Ehsani, H., Yousefi, H., Maknoon, R. (2016). Modeling landfill site selection by multicriteria decision making and fuzzy functions in GIS, case study: Shabestar, Iran. Environmental Earth Sciences, 75(4), 337-351.

Balali, V., Zahraie, B., Roozbahani, A. (2012). Integration of ELECTRE III and PROMETHEE II decisionmaking methods with an interval approach: application in selection of appropriate structural systems. Journal of Computing in Civil Engineering, 28(2), 297-314.

Bansal, S., Biswas, S., Singh, S.K. (2017). Fuzzy Decision Approach for Selection of Most Suitable Construction Method of Green Buildings. International Journal of Sustainable Built Environment, 6(1), 122-132.

Cabrerizo, F.J., Al-Hmouz, R., Morfeq, A., Balamash, A.S., Martinez, M.A., Herrera-Viedma, E. (2017). Soft consensus measures in group decision making using unbalanced fuzzy linguistic information. Soft Computing, 21(11), 3037-3050.

Chaudhary, P., Chhetri, S.K., Joshi, K.M., Shrestha, B.M., Kayastha, P. (2016). Application of an Analytic Hierarchy Process (AHP) in the GIS interface for suitable fire site selection: a case study from Kathmandu Metropolitan City, Nepal. Socio-Economic Planning Sciences, 53, 60-71.

Chen, J., Wang, J., Balezentis, T., Zagurskaite, F., Streimikiene, D., Makuteniene, D. (2018). Multicriteria approach towards the sustainable selection of a teahouse location with sensitivity analysis. Sustainability, 10(8), 2926-2940.

Cheng, S., Chan, C.W., Huang, G.H. (2003). An integrated multi-criteria decision analysis and inexact mixed integer linear programming approach for solid waste management. Engineering Applications of Artificial Intelligence, 16(5), 543-554.

Dey, P.K., Ramcharan, E.K. (2008). Analytic hierarchy process helps select site for limestone quarry expansion in Barbados. Journal of Environmental Management, 88(4), 1384-1395. 
Eskandari, M., Homaee, M., Mahmodi, S. (2012). An integrated multi criteria approach for landfill siting in a conflicting environmental, economical and socio-cultural area. Waste Management, 32(8), 1528-1538.

Grattan-Guiness, I. (1975). Fuzzy membership mapped onto interval and many-valued quantities. Zeitschrift für mathematische Logik und Grundlagen der Mathematik, 22(1), 149-160.

Hasanzadeh, M., Danehkar, A., Azizi, M. (2013). The application of analytical network process to environmental prioritizing criteria for coastal oil jetties site selection in Persian Gulf Coasts (Iran). Ocean \& Coastal Management, 73, 136-144.

Jahn, K. (1975). Intervall-wertige mengen. Mathematische Nachrichten, 68, 115-132.

Kahraman, C., Oztaysi, B., Sari, I.U., Turanoglu, E. (2014). Fuzzy analytic hierarchy process with interval type-2 fuzzy sets. Knowledge-Based Systems, 59, 48-57.

Kahraman, C., Keshavarz Ghorabaee, M., Zavadskas, E.K., Cevik Onar, S., Yazdani, M., Oztaysi, B. (2017). Intuitionistic fuzzy EDAS method: an application to solid waste disposal site selection. Journal of Environmental Engineering and Landscape Management, 25(1), 1-12.

Keshavarz Ghorabaee, M., Zavadskas, E.K., Olfat, L., Turskis, Z. (2015). Multi-criteria inventory classification using a new method of Evaluation Based on Distance from Average Solution (EDAS). Informatica, 26(3), 435-451.

Keshavarz Ghorabaee, M., Zavadskas, E.K., Turskis, Z., Antucheviciene, J. (2016). A New Combinative Distance-Based Assessment (CODAS) method for multi-criteria decision-making. Economic Computation \& Economic Cybernetics Studies \& Research, 50(3), 25-44.

Keshavarz Ghorabaee, M., Amiri, M., Zavadskas, E.K., Hooshmand, R., Antucheviciene, J. (2017). Fuzzy extension of the CODAS method for multi-criteria market segment evaluation. Journal of Business Economics and Management, 18(1), 1-19.

Kulak, O., Kahraman, C. (2005). Fuzzy multi-attribute selection among transportation companies using axiomatic design and analytic hierarchy process. Information Sciences, 170(2-4), 191-210.

Kwong, C.K., Bai, H. (2003). Determining the importance weights for the customer requirements in QFD using a fuzzy AHP with an extent analysis approach. IIE Transactions, 35(7), 619-626.

Liao, H., Xu, Z., Herrera-Viedma, E., Herrera, F. (2018). Hesitant fuzzy linguistic term set and its application in decision making: a state-of-the-art survey. International Journal of Fuzzy Systems, 20(7), 2084-2110.

del Moral, M.J., Chiclana, F., Tapia, J.M., Herrera-Viedma, E. (2018). A comparative study on consensus measures in group decision making. International Journal of Intelligent Systems, 33(8), 1624-1638.

Morente-Molinera, J.A., Kou, G., Pang, C., Cabrerizo, F.J., Herrera-Viedma, E. (2019). An automatic procedure to create fuzzy ontologies from users' opinions using sentiment analysis procedures and multi-granular fuzzy linguistic modelling methods. Information Sciences, 476, 222-238.

Mousavi, S.H., Danehkar, A., Shokri, M.R., Poorbagher, H., Azhdari, D. (2015). Site selection for artificial reefs using a new combine Multi-Criteria Decision-Making (MCDM) tools for coral reefs in the Kish IslandPersian Gulf. Ocean \& Coastal Management, 111, 92-102.

Rodriguez, R.M., Martinez, L., Herrera, F. (2012). Hesitant fuzzy linguistic term sets for decision making. IEEE Transactions on Fuzzy Systems, 20(1), 109-119.

Roy, B. (1991). he outranking approach and the foundations of ELECTRE methods. Theory and Decision, 31(1), 49-73.

Saaty, T.L. (1980). He Analytic Hierarchy Process: Planning. Priority Setting. Resource Allocation. New York International Book Company, MacGraw-Hill.

Saaty, T.L. (1996). Saaty, Decision Making with Dependence and Feedback: The Analytic Network Process. RWS Publications, Pittsburgh.

Sambuc, R. (1975). Fonctions Ф-Floues. Application Láide au Diagnostic en Pathologie Thyroidienne. Univ. Marseille, France.

Smarandache, F. (2005). Neutrosophic set-a generalization of the intuitionistic fuzzy set. International Journal of Pure and Applied Mathematics, 24(3), 287-295.

Torra, V. (2010). Hesitant fuzzy sets. International Journal of Intelligent Systems, 25, 529-539.

Turskis, Z., Lazauskas, M., Zavadskas, E.K. (2012). Fuzzy multiple criteria assessment of construction site alternatives for non-hazardous waste incineration plant in Vilnius city, applying ARAS-F and AHP methods. Journal of Environmental Engineering and Landscape Management, 20(2), 110-120.

Tuysuz, F., Simsek, B. (2017). A hesitant fuzzy linguistic term sets-based AHP approach for analyzing the performance evaluation factors: an application to cargo sector. Complex \& Intelligent Systems, 3(3), 167175 . 
Wang, Y.M., Yang, J.B., Xu, D.L., Chin, K.S. (2006). On the centroids of fuzzy numbers. Fuzzy Sets and Systems, 157(7), 916-926.

Xu, Z., Xia, M. (2011a). Distance and similarity measures for hesitant fuzzy sets. Information Sciences, 181(11), $2128-2138$.

Xu, Z., Xia, M. (2011b). On distance and correlation measures of hesitant fuzzy information. International Journal of Intelligent Systems, 26(5), 410-425.

Xu, Z., Zhang, X. (2013). Hesitant fuzzy multi-attribute decision making based on TOPSIS with incomplete weight information. Knowledge-Based Systems, 52, 53-64.

Yoon, K., Hwang, C.L. (1981). TOPSIS (technique for order preference by similarity to ideal solution) - a multiple attribute decision making. In: Multiple Attribute Decision Making-Methods and Applications, A Stateof-the-rt Survey. Springer-Verlag, Berlin.

Zadeh, L. (1965). Fuzzy sets. Information and Control, 8, 338-353.

Zadeh, L. (1975). The concept of a linguistic variable and its application to approximate reasoning-1. Information Sciences, 8, 199-249.

Zavadskas, E.K., Ustinovichius, L., Stasiulionis, A. (2004). Multicriteria valuation of commercial construction projects for investment purposes. Journal of Civil Engineering and Management, 10(2), 151-166.

Zavadskas, E.K., Turskis, Z., Kildiené, S. (2014). State of art surveys of overviews on MCDM/MADM methods. Technological and Economic Development of Economy, 20(1), 165-179.

Zavadskas, E.K., Bausys, R., Lazauskas, M. (2015). Sustainable assessment of alternative sites for the construction of a waste incineration plant by applying WASPAS method with single-valued neutrosophic set. Sustainability, 71(12), 15923-15936.

Zhang, Z. (2013). Hesitant fuzzy power aggregation operators and their application to multiple attribute group decision making. Information Sciences, 234, 150-181. 
A. Karasan is a research assistant at Yildiz Technical University in the Industrial Engineering Department. He received his BS degree in Industrial Engineering Department from the same university in 2013 and the MS degree in Industrial Engineering Department from the Istanbul Technical University in 2016. He is currently working toward the PhD degree in industrial engineering at the Istanbul Technical University. His research areas are decision making under uncertain environments, multi-criteria decision-making methods, occupational health and safety analysis, fuzzy sets and their extensions and fuzzy inference system. He has several publications in the mentioned areas.

E.K. Zavadskas is a professor of the Department of Construction Management and Real Estate, director of Institute of Sustainable Construction, and chief research fellow of Laboratory of Operational Research at Vilnius Gediminas Technical University, Vilnius, Lithuania. He has a PhD in building structures (1973) and DrSc (1987) in building technology and management. He is a member of the Lithuanian and several foreign Academies of Sciences. He is doctor honoris causa at Poznan, Saint Petersburg, and Kiev universities. $\mathrm{He}$ is the editor in chief and a member of editorial boards of a number of research journals. He is an author and co-author of more than 400 papers and a number of monographs. Research interests are building technology and management, decision-making theory, automation in design and decision support systems.

C. Kahraman is a full professor at Istanbul Technical University. His research areas are engineering economics, quality control and management, statistical decision-making, multi-criteria decision-making and fuzzy decision making. He published about 250 journal papers and about 180 conference papers. He became the guest editor of many international journals and the editor of many international books from Springer and Atlantis Press. He is the member of editorial boards of 20 international journals. He organized various international conferences. He was the vice dean of ITU Management Faculty between 2004-2007 and the head of ITU Industrial Engineering Department between 2010-2013.

M. Keshavarz Ghorabaee received the BS degree in electrical engineering from the University of Guilan, Rasht, Iran, in 2010 and the MS degree in production management from the Allame Tabataba' $i$ University, Tehran, Iran in 2013. He has published some papers in leading international journals. His research interests include multi-criteria decision making (MCDM), multi-objective evolutionary algorithms, genetic algorithm, fuzzy MCDM, inventory control, supply chain management, scheduling and reliability engineering. 